\title{
China: Towards a new model of development
}

\author{
Joseph E. Stiglitz*
}

The Columbia Business School, Columbia University, New York, USA

(Final version received 18 March 2007)

\begin{abstract}
This essay argues that changes in China's circumstances require a different model for the Chinese economic development. Because China's circumstances are different from that of other countries, the model for China inevitably needs to be different from that of elsewhere. In line with the central ideas, the essay discusses extensive issues regarding China's economic development such as export growth model, innovation, property rights, tax policy, social insurance, etc.
\end{abstract}

Keywords: Economic development; China's economic development; market mechanism; government intervention

\section{Introduction}

China's success over the past 30 years, since it began its transition to a market economy has been based, in no small measure, on the adaptability of its strategies and policies: as each set of problems was solved, new problems presented themselves, for which new policies and strategies had to be devised. It has also been based on social innovation. Because the problems confronting China were different from those that confronted other countries, new solutions had to be found. ${ }^{1}$ And it recognized that it could not simply transfer economic institutions (even when they had worked well in other countries); at the very least, they had to be adapted. Not only did the circumstances and history of China differ, but so, too, to a large extent did its objectives. These were among the reasons that China talked of a market economy with Chinese characteristics. And even successful Chinese institutions had to be modified and adapted as times changed. The Township and Village enterprises, itself a social innovation so central to the successes of the 1980s and early 1990s, could not meet all the challenges that China faced as it became an increasingly important player in the global economy.

Last year, China, in announcing its 11th Five-Year Plan, focused on some of the problems that its past successes had presented. Not everyone had benefited equally from the rapid growth of early decades; and though there was enormous success in reducing poverty, ${ }^{2}$ inequality had grown enormously. ${ }^{3}$ The greater reliance on markets had meant that in some dimensions, such as health and education, living standards in some rural areas probably had deteriorated. More broadly, Amartya $\mathrm{Sen}^{4}$ has argued that while in 1979, the life expectancy of China and India's state of Kerala were roughly the same,

\footnotetext{
*Email: jes322@ columbia.edu 
today, Kerala has a life expectancy four to five years longer than that of China. Kerala's GDP per capita growth has been less, but it has put greater priority on improving health. ${ }^{5}$ The rapid growth had also put enormous strains on the environment, and it was clear that such growth was not sustainable over the long run. The path that was being taken was not consistent with its articulated social objectives of a harmonious society, and a new direction was needed. At the same time, the rapid economic growth provided some of the resources that would enable China to address these problems, provided the government was able to collect sufficient revenues.

It was necessary, of course, to continue rapid growth, if China was to provide jobs for the burgeoning population, and if it was to have the resources required to meet the vast social needs. But other countries have shown that even rapid growth may not lead to a growth of jobs; there can only be job growth if output grows more rapidly than productivity. And even rapid growth may not lead to increases in living standards for most individuals in society. ${ }^{6}$

Last year, in my remarks to the China Development Forum, I talked about some of the economic principles underlying the 11th Five-Year Plan, discussing them in terms of standard economic concepts that had helped clarify the roles that government needed to take in a modern economy. ${ }^{7}$

Today, China is focusing on implementing the 11th Five-Year Plan, and my remarks will focus on certain aspects of that implementation. ${ }^{8}$ But these issues have to be in context. In certain key ways, China's 11th Five-Year Plan is based on a New Economic Model, a model that is different from that which it followed in the past, and different from that which is being followed by many Western economies. ${ }^{9}$ And to understand the New Economic Model, one has to understand why the old model worked as well as it did, the problems which it confronted, and how the New Model addresses those problems. Most important in this respect are: (a) why export led growth was so important in the past, but why the functions which it served can now be met in new and better ways; and (b) why China needs an independent innovation system.

\section{Export led growth}

China's success, like that of most other East Asian countries, was based on export led growth. Its 11th Five-Year Plan called for a move away from this model, to one based more on domestic consumption and investment. Of course, exports will continue to play an important role. The question is a rebalancing of its growth model.

Globally, its successes in exporting were not being well received by many elsewhere who saw their jobs being threatened. It was one thing to talk about the virtues of competition and the market, it was quite another thing for those countries to lose in the market game, and in many quarters, shrill protectionism sentiments began to be heard. The excess of exports over imports helped stimulate China's economy, but had exactly the opposite effect on others.

The trade surplus allowed China to accumulate large amounts of reserves, which could help protect China against the volatility of the global market place. Other countries had learned the hard way, for example, in the East Asia crisis the risks of not having sufficient reserves. China did not want to go through these experiences itself. Still, China had accumulated more than a trillion dollars of reserves, more than ample to meet any crisis. Yet an increase in the exchange rate would still have an adverse effect on the rural sector, potentially increasing the divide between incomes in the rural and urban sector. China's export sector might survive an increase in the exchange rate, though it would do 
little for global imbalances, and might even make matters worse, since it would make the problem of financing the US trade deficit more difficult $;^{10}$ but China faced the dilemma: if it appreciated the currency, and subsidized its farmers - to, in effect, countervailing the subsidies provided by the US and the EU, it would take away scarce money needed for other developmental objectives, including investments in education and health.

\subsection{Alternative measures for moving away from exports}

There is a need for other measures to correct the trade imbalances that would not simultaneously increase rural urban differentials. One such measure is an export tax or reduced export rebates, ${ }^{11}$ which have the further advantage of providing additional revenues that could be directed at other social objectives.

Many of China's exports are energy intensive, with societal costs that go well beyond the costs borne by firms. Raising the price of energy and imposing a carbon tax and other environmental taxes (to be discussed further below) would help adjust the structure of the economy - including helping China move away from exports - and again provide additional revenues that could be directed at other social objectives.

\subsection{Why export-oriented growth}

It is natural to ask: Why did export-led growth work for China and for so many of the other East Asian countries? Will the move away from export led growth adversely affect its growth? Are there other ways in which the needs it satisfied can be met?

Export-led growth was important for three reasons. Firstly, it provided the basis of innovation. What separates developing and developed countries is not just a gap in resources, but a gap in knowledge. As Greenwald and Stiglitz (2006) point out, for a variety of reasons the transmission of knowledge is enhanced the larger the size of the industrial sector. The skills learned in that sector then gradually are transmitted to the rest of the economy. Secondly, there is intense competition in exports, and competition spurs efficiency and innovation. Success requires meeting international standards, again a benefit that extends eventually throughout the economy. Thirdly, in the early stages of development, the capacity to produce may outstrip the capacity to consume, or more accurately, the expansion of the demand for the particular goods that are being produced. While there may be latent demands by many households and firms, these latent demands are translated into effective demands only if these households and firms can get access to credit. But in the earlier stages of development, financial institutions (and the underlying legal infrastructure) that can discriminate between those who are creditworthy and those that are not and that can enforce credit contracts often have not developed. ${ }^{12}$ It is easier to lend abroad to finance foreigners' consumption than to lend at home.

Indeed, China can be viewed in recent years as having been engaged in vendor finance: it has lent much of the money that has enabled those elsewhere to buy its goods. ${ }^{13}$ But there is something peculiar about China helping the richest country in the world to live beyond its means, ${ }^{14}$ when there are so many pressing needs at home.

\subsection{Why China today can move away from export-led growth}

Today, these functions that export-led growth has served can be accomplished in other ways. China is establishing a broad innovation system (see below); it has 'learned how to learn'; it does not need to rely on exports for learning. China has created vibrant internal competition, e.g. among TVEs and other establishments. To be sure, there is a 
need for strong competition laws to ensure that domestic competition remains strong, and China should be wary of those arguing for the establishment of large 'national champions,', at least when the establishment of those national champions threatens domestic competition. ${ }^{15}$

Finally, China has made great strides in creating a strong domestic financial system. It would be easy, at this stage, to expand domestic credit, especially for housing and collateralized debt. ${ }^{16}$

\subsection{Stimulating consumption}

In spite of the talk about moving away from export led growth, China's trade surplus has actually increased from 102 billion US dollars in 2005 to 177.5 billion US dollars in 2006. ${ }^{17}$ Household consumption has increased, but it has not increased as fast as GDP. ${ }^{18}$ Expanding consumption would not only help China move away from its dependence on exports, but would contribute to rising living standards - and the objective of development is raising living standards. The question is: Why has China had 'excessive" savings? There are four hypotheses; each plays a role, though some may be more important than others.

The first is growing inequality. With consumption propensities among the rich typically lower than among the poor, ${ }^{19}$ an increase in inequality will result in a lower ratio of consumption to GDP. Policies that reduce the degree of inequality would, accordingly, be expected to increase consumption.

The second is capital market imperfections, especially those facing small- and medium-sized businesses. Some data suggests that the number of small businesses in urban areas have declined; ${ }^{20}$ historically, small businesses are associated with job growth. They are especially important in providing new opportunities for those that in the past had none. Many contend that small businesses are at the heart of a dynamic economy - while large businesses bring products to market, they depend on a host of small businesses for the real innovations. A decline, or even stagnation, in the number of small businesses should, accordingly, be a cause of concern. One of the reasons that has been posited for the decline in small businesses is lack of access to capital. Large banks prefer lending to large businesses. In the United States, there is a special government program through the Small Business Administration to encourage lending to small businesses, through absorption of some of the risk.

In the absence of access to funds, those who would aspire to be small businessmen - or those already in small businesses - have to save at a very high rate to have the funds they need to expand. Hence, improving access to credit would help lower the overall savings rate. But the major barrier to increasing consumption is not lack of credit, but the lack of an effective social safety net, a strong public health system,${ }^{21}$ an effective social security system, and good publicly provided education. 'Precautionary' savings depresses consumption. These reforms would thus yield a double benefit, freeing China from its dependence on exports (and the vagaries of international markets) as it improves standards of living.

The final reason for a high ratio of savings to $\mathrm{GDP}^{22}$ is the high current account surplus, symbolized by the large additions to reserves. In 2006, these amounted to $7 \%$ of GDP. At the same time, the government has maintained a strong fiscal position. But as we noted before, China has accumulated enough reserves to meet any plausible variability in the market place. Given the high social needs in health and education - and its high private savings rate - China could well afford to have a modest fiscal deficit (see Feldstein 2007).

Less reliance on exports could, of course, be achieved by expanded investment; but with China's investment rate as high as it is, the issue today is not so much the level of 
investment but its allocation. The worry is that there is a perverse set of incentives at play - with local communities rushing in to encourage investment, both to generate jobs and revenues for themselves. Especially in real estate, there is a concern that short-sighted investors are focusing on short-term capital gains rather than long-term returns.

\section{Innovation}

At the centre of the new economic model is innovation - increasing the efficiency with which scarce resources are used. Innovation is endogenous, the result of allocation of resources to R\& D and conscious policies attempting to learn how to produce 'at the frontier or adopt the best practices as it is sometimes put'. ${ }^{23}$ But resources devoted to research and learning are, like all resources, scarce. One can direct such research at different objectives. Unfortunately, Western firms have directed their research too much at reducing the input of labour, and too little at reducing environmental impacts.

The problem is that the social returns to innovation differ from the private returns, both because of distortions in markets and because the private returns to obtaining a patent differ markedly from the social returns

\subsection{Excessive incentives for labour-saving innovations}

For instance, high wages in the West mean that there is a high return to reducing labour input. Even in countries where the unemployment rate is high, there are large investments in labour-saving technologies, exacerbating the unemployment problem. The focus on labour-saving innovations is the reason that so many countries face growing problems of unemployment. If productivity increases at 5\% a year, output has to increase at $5 \%$ a year just for employment to remain constant.

Indeed, for the owners of the firms in the industrial sector, there is a further benefit from the increasing unemployment: the higher unemployment rate serves to depress wages, lowering the cost of production further. For a 'harmonious society', however, jobs have to be created to match new entrants into the labour force. In the case of China, the pace of urban job creation needs to be even greater, as labour migrates from the rural to the urban sector. And higher wages are not a bad thing: the whole purpose of development is to increase the wellbeing of workers.

\subsection{Insufficient incentives for resource saving innovation}

By the same token, because American firms do not pay anything for carbon emissions regardless of the cost imposed on the global economy - they have no incentive to look for innovations that reduce carbon emissions. Making firms pay the full marginal social costs of their activities - the cost, say, of carbon emissions - would enhance incentives for pollution reducing innovation.

A carbon tax would have, in addition, one further important advantage. It could break the global impasse on what to do about global warming. The scientific evidence about the risks of this impending calamity has been mounting. The UK Stern Report (2006) made a convincing case that the economic benefits - taking into account all the risks of doing something to mitigate the risks outweighed the costs. ${ }^{24}$ The Kyoto protocol was based on emission targets determined on the basis of reductions from the 1990 levels of emissions. Unfortunately, no one has come up with a set of principles that would guide the determination of emission target levels in a fair and equitable way, which would be acceptable to both the developing countries and the US. Because the distributional 
consequences of a common policy - each country would agree to impose a carbon tax, at rates reflecting the agreed upon global social cost of carbon emissions - are much more limited, there may be some hope of a global agreement. ${ }^{25}$ Besides, it makes so much more sense to tax bads - like pollution - rather than goods, like work and savings.

\subsection{Fundamental problems in designing an innovation system in a market economy}

The problem with the innovation system in market economies is, however, deeper. It is often suggested that intellectual property is at the centre of the market economy's innovation system. But the rewards provided by the patent system do not accord well with social returns. The marginal social return to innovation is making the innovation available sooner than it otherwise would have been. But the patent system gives the (temporary) property right to the first person to discover (or more accurately, to patent) the innovation.

For instance, consider the case of the human genome. There was an international effort to decode the human genome. This effort was on track when some firms decided to try to 'beat' the publicly funded project. If they beat them even by one hour, they got all the benefits of the monopoly - even though their marginal social contribution was nil.

But while in these cases, the benefits are nil, the cost of the patent system to society is huge. Knowledge is a public good; knowledge is 'non-rivalrous'. When one person tells a piece of knowledge to another, it does not detract from what the first person knows. Restricting the use of knowledge is inefficient. But the patent system not only restricts the use of knowledge, it also gives the exclusive right to the use of that knowledge to one party - it creates an artificial monopoly, and monopolies distort resource allocations. In the case of medicines, what is at stake is not only money, but lives themselves. Monopolists may charge a price so high that the poor cannot afford the medicine; thousands, perhaps hundreds of thousands, of individuals may die unnecessarily as a result, especially when there is an inadequate public health system. As a result of the patent on the gene that shows a strong likelihood of breast cancer, the owner of the gene insists on a large payment for every test performed. The resulting $\$ 3,000$ fee puts the test out of the range of anyone without health insurance, and even in a rich country like America, more than 50 million Americans do not have health insurance. The result is that thousands of people will die unnecessarily.

The only justification for this enormous cost of static inefficiency associated with the patent system is that there may be dynamic gains. But if the intellectual property regime is not well designed, the costs will outweigh the benefits. An intellectual property regime is defined by a whole set of detailed provisions, which describe what can be patented (or copyrighted), the standards of novelty, the life of the patent, the breadth of the patent, the process by which patents are granted and challenged, and the enforcement mechanism. Indeed, a poorly designed intellectual property regime can even stifle innovation. The worry today in America is that its intellectual property regime is doing just that. The increasing concerns are leading to an active debate about the reform of the intellectual property regime in the US. ${ }^{26}$ At the very least, those outside the United States should recognize that the mantra that one hears from certain corporate leaders and government officials - that the stronger the intellectual property regime, the better - does not reflect the mainstream of thinking among economists and academic intellectual property lawyers who are not in the employ of the corporations that derive so much of their profits from the current regime. 


\subsection{Designing an innovation system for China}

Every country has to have an intellectual property regime that is appropriate to its own circumstances. ${ }^{27}$ It has to balance the costs and the benefits; and in general, the way that is done will differ markedly between developed and developing countries. That is why at the World Intellectual Property Organization, the developing countries have demanded a development-oriented intellectual property regime. We noted earlier that one of the main challenges facing developing countries is reducing the gap in knowledge that separates them from more developed countries. A poorly designed intellectual property regime may make it more difficult to close that gap. The worry is that under the influence of TRIPs, many countries are adopting American-style intellectual property regimes, which, as badly suited as they may be for America, are even more ill-suited for developing countries - and just at a time when America itself may be realizing that reform is needed.

A well-designed innovation system consists of a portfolio of instruments, including government-financed research (supporting research at universities, specialized laboratories, and even corporations), prizes, and patents. A prize system provides a reward - a large prize for innovations of high social value, such as a cure for an important disease like malaria, a small prize for a me-too medicine - but then the knowledge is made available to anyone who wants to use it with perhaps a licensing fee. ${ }^{28}$ Of course, the patent system is a prize - the award of a distortionary monopoly power. But while the patent system is designed to restrict the use of knowledge and raise prices, the prize system uses the power of the market economy and competition to ensure the lowest possible prices and the greatest dissemination of the knowledge, so that the benefits of the knowledge are enjoyed by as many people as possible.

China needs to have an innovation system that puts greater emphasis on prizes and government-funded research, and less emphasis on patents than does, say, the US system, especially because the innovation needs to be directed at a broad range of social objectives that I noted earlier - as I argued, the focus should be on reducing inputs of environmentally sensitive resources, not on saving labour. ${ }^{29}$

\subsection{Learning lessons from other countries}

But even when it comes to the intellectual property regime, China should learn the appropriate lessons from the deficiencies in America's intellectual property regime, which have become even clearer during the past year, since I talked about these issues briefly in my talk before the China Development Forum. It does not need to repeat the same mistakes. It needs to think carefully, for instance, about procedural issues (challenging patents before they are issued), recognizing that there is in fact a bias leading to overpatenting. There are strong private incentives to try to get a patent - one can privatize part of the public domain of knowledge; ${ }^{30}$ but challenging a patent provides a public good, a conversion of what otherwise would have been in the private domain, making it publicly available. There will, accordingly, be an undersupply of challenges; designing the intellectual property regime procedures can go a little way to redressing this imbalance. There are other issues concerning the scope of the patent and the standards of 'novelty', what can be patented, enforcement procedures - compensation for 'trespass', i.e. a liability system as opposed to the current American system, the duration of copyrights, ${ }^{31}$ etc.

The TRIPs agreement puts obligations on all member countries to adopt an intellectual property regime; but even within TRIPs, member countries have considerable discretion, and it is important that China use that discretion to create an intellectual property regime that is appropriate for China. While I have described several features of the design of such 
an intellectual property regime above, I want to draw attention to one other feature: the use of compulsory licenses. TRIPs provided for 'flexibilities' for the issuance of these, allowing the production of generic medicines, which can sell for a fraction of the cost of brand name medicines. Most countries, including China, have not made full use of these flexibilities, which can make such a difference to the health of the citizens of the country. ${ }^{32}$

\section{Creating the institutions for a market economy}

This brief discussion of the innovation system illustrates several important themes of the New Model for China's development. Firstly, success in this New Model will require recognizing the important differences between the objectives that China is now pursuing, and those that are at the centre of at least many of the market economies, focusing exclusively on an increase in GDP. But it will also require recognizing that even in terms of that narrower objective, Western market models often fail, and that there are a range of approaches taken within different Western countries. Those in the West who are concerned with broader social objectives in particular are themselves often critical of some of the particular institutional arrangements that have been adopted. To take an example, the US recently reformed its bankruptcy law in ways that may significantly disadvantage those who cannot repay what they owe for reasons beyond their control, for instance as a result of a serious illness. At the very least, it is a contentious change that its opponents believe may contribute to an increase in social distress.

Secondly, one has to recognize that 'one size fits all policies' almost never work and that transplanting institutional arrangements such as America's intellectual property regime to China would be a mistake. Some adaptation is always required; but in many cases, given the differences in circumstances and objectives, the differences in the appropriate institutional arrangements are so large that it would be a mistake to begin with, say, the American model as a template.

Thirdly, there are many different forms of a market economy; the American model is, in many ways, markedly different from the Scandinavian model, the Continental European Model, or the Japanese model. These countries differ in their history, their social context, and their articulated social objectives. The Scandinavian model puts more emphasis on social solidarity and social justice and exhibits more concern for the poor. The Scandinavian countries have succeeded in achieving much higher levels of performance in terms of broader indicators of societal wellbeing (such as the UNDP's Human Development Indicator) than the United States, even though their growth has been robust. They have also been highly innovative, with the penetration of new technologies again scoring towards the top in the world. ${ }^{33}$

Fourthly, many of the discussions of institutional design issues (such as those on property rights) are based not on an understanding of the actual features and workings of those institutions in particular Western countries, but on an academic idealization a version of those institutions that some extreme groups might advocate, but that would never have been adopted in practice. For instance, while some free market economists have advocated a basically private retirement insurance program, the United States has repeatedly rejected the notion of even partially privatizing its public social security system, most recently following the proposals of President Bush to partially privatize social security in January 2005. Government provision entails far lower administrative costs,$^{34}$ provides insurance against risks (like the risk of inflation) that private markets typically do not provide, and can achieve redistributive objectives (reducing poverty and reducing 
intergenerational inequality) that are otherwise difficult to realize (see, e.g. Orszag and Stiglitz 2001, 17-56).

Fifthly, the details of institutional arrangements are often critical (or as the English aphorism has it, 'the devil is in the details'). We saw this in our earlier discussion of intellectual property rights. Many of the problems of America's intellectual property regime lie in details, about how intellectual property rights are enforced, the breadth of patents, and how patents are granted. A discussion that simply says, 'One should have strong intellectual property rights' doesn't take one far.

Sixthly, especially because the details are so important, there are often unintended consequences of well-intentioned policies. In solving one problem, new, unanticipated problems are created.

In the following paragraphs, I comment briefly on several issues that are currently being discussed as part of the implementation of China's 11th Five-Year Plan, in light of the general principles just discussed. The design of the institutions and policies which will help implement the New Model of China's Economic Development will be at the heart of the success of this endeavour, and in the limited amount of time, I can only touch upon a few further examples.

\section{Property rights}

China has been discussing the adoption of a legal framework for property rights. Some argue that what is needed is 'strong property rights', and that strong property rights are the basis of the success of the market economy. Indeed, some go so far as to suggest that all the government needs to do is to enforce strong property rights. ${ }^{35}$

But even the formulation of this does not capture well property rights systems in the advanced industrial countries. Property rights are always restricted; for instance, owners of intellectual property rights still cannot use those in ways which are 'abusive', e.g. in an anti-competitive manner, as Courts in the US, EU, and elsewhere have repeatedly reminded Microsoft. ${ }^{36}$ In the United States, an owner of a tree on which an endangered species of bird has nested cannot cut the tree down. Throughout the UK, there are rights-of-way that allow walkers to enjoy the countryside.

And property rights are always accompanied by responsibilities. A person who owns a tract of land, for instance, has the responsibility to make sure that it is not used as a toxic waste dump, and if it is and if as a result ground water underneath is polluted, the owner of the property has the responsibility of cleaning up the mess, even though he did not create it.

The balance of rights and responsibilities and the nature of the restrictions which society imposes on those rights and responsibilities are at the heart of the design of institutional arrangements for property rights. It is a complex matter, and simplistic discussions that simply say we must ensure secure property rights do little to advance either our understanding of what needs to be done or how to do it.

\subsection{Balance}

The emphasis of many on property rights - ignoring the importance of responsibilities is paralleled by another imbalance, in the setting of the agenda. Too little attention is sometimes paid to other rights, e.g. workers' rights or consumer rights. Indeed, these rights are, in some ways, more fundamental because property rights are only instrumental, that is, of importance because of their consequences, for instance, for economic efficiency 
and therefore, indirectly, to societal wellbeing; while these other rights affect directly the wellbeing of citizens.

Discussions of workers' rights or consumer rights highlight the linkage of rights and responsibilities, and the nature of rights and responsibilities in defining relationships among individuals (or corporations) with each other and with the government. Thus, firms have responsibilities to consumers, e.g. with respect to the safety and the quality of what they produce. Workers' rights help define firms' responsibilities to their workers.

That is why any agenda emphasizing 'harmony' must have a balanced discussion of property rights and of the rights of workers or consumers, and a balanced discussion of responsibilities as well as rights.

\subsection{Unintended consequences}

One of the motivations for strengthening property rights arises from local government taking land away from farmers for development purposes, without 'fair' compensation. This is clearly a problem that needs to be redressed. But poorly designed property rights laws could allow individuals to borrow against the land, and then, if he cannot repay, lose title to the land. The result could be the creation of large numbers of landless workers. Not only could this have large social consequences, but it could even have adverse consequences on economic efficiency. ${ }^{37}$

\section{Tax policy}

In earlier stages of development, China felt it needed to attract foreign investment; it worried that there was a shortage of entrepreneurs, capital, and technology at home. But this has all changed, and it makes little sense to give foreigners in general preferential tax treatment over domestic entrepreneurs. Indeed, there are arguments going in the contrary direction: spill-overs from the expansion of domestic entrepreneurship may be greater, so that some preferences should be given to domestic firms. Moreover, many foreign firms face tax systems where tax credits are given for foreign taxes paid, so that raising tax rates on foreign firms may have little effect on incentives, and simply constitute a redistribution from foreign governments to China's government.

But equalizing tax rates may not suffice. What matters are the details - provisions, for instance, concerning depreciation and other expenses. Many Western companies are adept at tax avoidance, paying no taxes even though the legislated rate is, say, $25 \%, 30 \%$, or higher.

In a market economy, tax policies play an important role in resource allocation. Three of the objectives of the New Model discussed earlier include: (a) protecting the environment and reducing resource utilization; (b) moving away from export-led growth to growth based on domestic consumption and investment; and (c) redressing the growing inequalities. The consumption-based VAT pays no attention to the environment, is regressive (in the usual definition, since lower income individuals consume a larger fraction of their income); and discourages consumption. Thus, while the tax might make sense for other economies, which are concerned with encouraging savings, it makes little sense for China. ${ }^{38}$ What does make sense, as I noted earlier, are the imposition of taxes on carbon emissions, and the design of tax structures which encourage recycling. Given worries about excessive real estate investment, and given the difficulties of designing administrative measures that deal with the problem effectively, it also makes sense to have high capital gains taxes on real estate (as well as other speculative activities). 
There are other tax reforms that could facilitate China's structural adjustment according to the New Economic Model. There are large costs associated with private cars in congested urban areas, and they should accordingly bear high taxes. The current tax structure may disadvantage services, and shifting from a turnover tax to a VAT would both increase efficiency and encourage the development of this sector.

Finally, China will need additional public revenues to finance its social, environmental, and developmental agenda. China could clearly collect a substantially higher fraction of GDP in taxes, without adversely affecting its growth. The Scandinavian countries have shown that even very high tax rates are consistent with rapid growth and high levels of innovation. These high tax rates help explain why, on broader measures of social wellbeing, these countries outperform other countries. Indeed, increasing taxes on pollution could generate government revenues, improve the environment, and enhance long-term growth.

Similarly, earlier we noted that China no longer needs to continue to build up its reserves. But increasing its exchange rate would have several adverse effects, including lowering the incomes of farmers. Offsetting the effect of America and Europe's huge agricultural subsidies would divert resources needed for other social and developmental objectives. An export tax (or, at a minimum, eliminating export rebates of VAT) would, by contrast, both reduced the trade gap and generate additional revenues.

\section{Financial markets}

Financial markets play a key role in any market economy, because of their importance in allocating resources. Financial markets do more than intermediate between savers and investors. They gather and process information, determine who is credit worthy, which investments are most likely to yield high (risk adjusted) returns, and enforce credit contracts. But the thrust of my research was to show that market failures are endemic when information is imperfect, and that there is an important role for government in financial markets. Few today question the necessity of government regulation of banks and securities markets; the only debate is about the form and extent of the regulation.

There are a number of reasons that government regulation is both desirable and necessary. An understanding of these motivations helps shape policies. The first, already noted, is that market failures are endemic in markets where information is imperfect - and information imperfections are at the heart of financial markets. The second is the presence of large externalities, so evident in the East Asia crisis. Bad lending and borrowing practices are often blamed for the crisis - but the crisis touched everyone in the affected countries, not just the lenders and borrowers.

Government regulation needs to be directed at four objectives: (a) ensuring the safety, soundness, and stability of the financial system, recognizing that many of the economic fluctuations that have marked capitalism since its beginnings are related to weaknesses or other failures of the financial system; (b) protecting consumers (borrowers, investors) against abusive practices - especially important in a context where there are many uninformed and inexperienced investors; (c) ensuring competition, recognizing that even when there are many financial institutions, the market may be such that there may be limited competition in, say, the supply of loans to small or medium sized firms in a particular locale; and (d) ensuring access to credit, especially of underserved sectors and groups.

In accomplishing these objectives, the government will need to employ a portfolio of instruments, both market-based interventions and administrative measures. For instance, to 
ensure that banks do not engage in excessively risky lending, risk-based capital adequacy requirements and deposit insurance premiums may be used as part of market based measures.

\subsection{Access to credit}

Here, I want to touch on only four aspects. ${ }^{39}$ The first is that markets, by themselves, often fail to provide credit (or at least provide an adequate supply of credit at reasonable terms) to certain categories of potential borrowers. That is one of the reasons why even in highly developed financial markets like the United States government has intervened in financial markets to promote mortgages, student loans, credit for small- and mediumsized businesses, credit for underserved communities, and rural credit. The argument for such interventions in China, at its current stage of development, is even more compelling. Increasing the flow of credit in these areas is particularly important if China is to succeed in its objective of reducing the large disparities in income; and this is an example of a kind of government action that can both enhance growth and equality - and that may even help the structural adjustment of the economy away from exports.

In the United States (and many other countries), interventions have taken on a number of different forms, and China would probably benefit from using a wide portfolio of instruments: the creation of specialized banks and lending agencies; the imposition of lending requirements to underserved communities and sectors (cf. the US Community Reinvestment Act requirements); or the provision of partial guarantees or limited subsidies. India has imposed requirements the effect of which is to increase branches - and the availability of credit - in rural and more remote areas. Such requirements, if properly designed, can be made consistent with WTO obligation. Otherwise there is a temptation, especially of foreign banks, to engage in 'cream skimming', providing ample credit for large firms, but little credit, for instance, for domestic small- and mediumsized firms. Indeed, some recent studies suggest that in many countries, the entry of foreign banks has actually led to an overall decrease in credit to these enterprises.

Perhaps the most important thing that China should do is to encourage the entry of small- and medium-sized local banks. As I have argued elsewhere, the key to providing credit is information; local banks are more likely to be relatively well informed about local (small- and medium-sized) firms (Stiglitz and Greenwald 2002). Of course, China needs simultaneously to develop the capacity to regulate and supervise small- and medium-sized banks.

\subsection{Risks and rewards of capital and financial market liberalization}

The second is to recognize that capital or financial market liberalization, by itself, may not lead to faster growth, but may contribute to greater economic instability. Even the IMF, in its 2003 study (Prasad et al. 2003), has recognized that capital market liberalization had brought risk without reward in many developing countries. It found the result surprising contrary to economic 'theory' - but it was contrary only to an economic theory based on perfect information and infinitely lived individuals. More realistic models, based on imperfect information, ${ }^{40}$ are fully consistent with the empirical findings. The implication is clear: China must take extreme care as it liberalizes its financial and capital markets. Regrettably, I do not have time today to describe in greater detail the appropriate set of policies; but the complexity and risks strongly support a policy of gradualism. This is especially true because there is a learning process, both for investors, regulators, and financial firms. 


\subsection{Trade-offs among objectives}

The third is to recognize that there may be important trade-offs among various objectives. For instance, one can ensure the safety and soundness of the banking system by requiring banks to hold only short-term government bills; but if that were done, banks would not be able to fulfil one of their main functions: providing access to credit.

\subsection{Adapting to the evolving Chinese market economy}

The fourth is to recognize that the quickly evolving nature of China's economy and financial markets will require adaptable regulatory policies. For instance, as part of its WTO accession agreement, there will be entry of foreign financial firms. Previously, the financial system performed a number of social functions. It may not be possible for some of these to be accomplished through financial systems ${ }^{41}$ - and the greater transparency, e.g. of hidden subsidies, may be an ancillary benefit. In other cases, the ways in which these objectives are attained will have to be changed; for instance, in order for there to be adequate access to credit by small- and medium-sized firms, regulations such as CRA requirements discussed earlier may have to be imposed.

One important aspect of China's evolving market economy is the New Economic Model, which places greater emphasis on domestic consumption. As we noted earlier, one of the reasons that export-led growth played such a critical role in China's earlier development was that it allowed the country's productive capacity to expand more rapidly than its capacity to expand aggregate demand - its ability to ensure that investment expenditures would be well spent, and its ability to ensure that consumers who might gain access to credit would be able or willing to repay. Today, strengthened financial institutions have a greater capacity to provide consumer loans (including mortgages). But China should learn the lesson of other countries: financial institutions sometimes prey on uninformed consumers, charging them exorbitantly high interest rates, and this may be particularly the case in situations where consumers have little experience in debt. Moreover, they often lend beyond individual's capacity to repay, which can lead to stress on the part of consumers, and, when sufficiently large numbers are unable to repay, stress on the financial system as a whole. China needs strong consumer protection legislation, rigorously enforced, and backed up with a debtor-friendly bankruptcy law that gives lenders greater incentives to engage in due diligence to ensure that borrowers have the capacity to repay.

\section{Social insurance}

It is now widely recognized that one of the reasons that China has such a high savings rate is the absence of adequate social insurance, ${ }^{42}$ there are inadequacies in the public provision of education, health, and retirement programs. Stronger public support of these programs will help achieve two of the critical parts of the New Economic Model: it will help China in its move away from export-led growth and in its attempt to reduce the disparities in wellbeing among its citizens. ${ }^{43}$

But designing a good social insurance system is not easy, especially in a highly competitive global economy. As I noted earlier, the Scandinavian countries have shown that providing a strong social insurance program (including a strong public education system) can actually provide a country with a competitive advantage. Competing in the global market place requires a healthy, well-educated labour force, able to adapt to the fast pace of changes. With risk taking so essential to success, a strong social safety 
net - combined with high levels of employments - enhances the ability and willingness of individuals to undertake risk.

There is much discussion about the virtues of international trade - the gains provided by a larger marketplace. But the economic gains that result from creating a strong national economy are even larger. And a strong national economy requires labour mobility; and labour mobility requires a national social insurance system.

Moreover, in the past, firms both in China and elsewhere were engaged in two separate activities - production and the provision of social services. Competing in the global market place requires separating out these functions, and that means that the government must take on an increased role. As we noted earlier, there are sound economic and social reasons why the provision of at least a basic level of social insurance cannot be left to the market alone. Fortunately, China's rapid growth means that there should be the resources with which to begin to create a strong, national social insurance program.

\section{Liveable cities}

On several previous occasions, I have discussed the importance of the creation of liveable cities. China is rapidly urbanizing. ${ }^{44}$ An increasing fraction of China's population will live in urban areas, and how these urban areas are designed will have enormous effects, on the quality of life, the efficiency of the overall economy, and on the environmental impact of China's growth. Market forces by themselves will not lead to the creation of liveable cities, and there are built-in incentives both for certain government officials and for private sector entrepreneurs for the creation of urban sprawls and the design of urban spaces that are counter to the principles that should underlie liveable cities. It is especially important for governments to take action now, with a clear view of long-term consequences of land usage patterns: the decisions made today, e.g. with respect to the design of road networks, will have consequences for decades to come.

China has moved away from the planning model to a market system. But in this move away from planning and to the market, there may not be sufficient appreciation of the limits of the market. This is especially so in land usage. In most Western countries, city planning is critical - the externalities that naturally arise are too large to be ignored, too complex to be dealt with by a simple price system. The few cities that have tried to do without planning serve as a reminder of why city planning is so important. To be sure, zoning can also be a source of corruption both in the design of the plan and in the granting of variations; there is no alternative to implementing strong policies of good governance.

\section{Information systems}

Well-functioning economies require good information; but there are systematic market failures. Individuals often have incentives not to reveal relevant information, or worse, to provide distorted information. Much of my theoretical work has been devoted to understanding the problems that imperfect information poses for the functioning of a modern economy. ${ }^{45}$ I have stressed the importance of good accounting systems, as well as the dangers posed by certain conflicts of interest as well as the perverse incentives to which stock option systems may give rise.

Some of my more recent research has been concerned with information problems which arise within organizations, and in the public sector (see, for instance, Stiglitz 2003b). Governments, too, need to have good information in order to make good decisions. There are incentives of government officials not to disclose what is going on, either to citizens or to those to whom they are supposed to report. There is, of course, a need to have 
strong laws to avoid conflicts of interest just as there is a need for such laws in the private sector. And just as successful private sector managers have learned that there is a need to have a variety of channels of information, so, too, in the public sector. A vibrant, responsible media can be one such channel. For it to be effective, it has to have access to relevant information, which is why right-to-know laws ('freedom of information acts') can be so important. The press also, of course, must be responsible; designing appropriate libel laws is important. Unfortunately, such laws have often been abused, and in some countries have vitiated the benefits which would come from an active and vibrant press.

\section{Concluding remarks}

I have argued here that China's circumstances have changed, and that requires a different model - and because China's circumstances are different from that of other countries, the model for China inevitably needs to be different from that of elsewhere.

Some three decades ago, China set forth on a new course. It talked about a pragmatic policy of 'crossing the river by feeling the stones'. The pragmatism that underlies this approach is partially responsible for China's enormous success.

Now that China has gone more than half way across the river, what is on the other side is clearer. It is clearer that there are many different forms of a market economy many different places to land on the other side of the river. China can now see that it can make a great deal of difference the directions which it takes. What kind of market economy it chooses will affect what kind of society it will create.

Even as China crosses the river by feeling the stones, creating a market that is consistent with China's distinct circumstances and objectives will require a New Economic Model. China's 11th Five-Year Plan reflected this New Economic Model. In this paper, I have tried to lay out some of the economic foundations underlying this New Economic Model and to suggest some of the implications it may have for the design of policies and institutions.

\section{Acknowledgements}

This essay is a revised version of remarks given at the China Development Forum, Beijing, in March 2007. I am indebted to Mo Ji for helpful comments and suggestions, as well as to conversations over the years with Larry Lau and Justin Yifu Lin, David Dollar, Xie Fuzhan, Zhou Qiren, as well as other participants in previous meetings of the China Development Forum. Justin Lin provided detailed comments on this draft, for which I am particularly grateful.

\section{Notes}

1. An example is China's use of the dual price system in the transition from the prices that prevailed under planning to more market-based prices.

2. In the past two decades, 2.2 hundred million Chinese people have overcome absolute poverty, which accounts for $75 \%$ of the population of poverty reduction in developing countries.

3. One standard measure of inequality is the Gini coefficient. China's Gini coefficient increased from 0.16 (before reform) to 0.47 (after 2005). By contrast, the US Gini coefficient stands at 0.466, Japan's at 0.249 , and the Scandinavian countries at around 0.3. See http://www.forbes.com/free_forbes/2005/1010/064.html.

4. See his lecture 'Human development and health' (Sen 2006). Sen also points out that Kerala's life expectancy is higher than that in every province of China, except for the urban conglomerates such as Beijing and Shanghai. Infant mortality rates were comparable in 1979; now Kerala's is one third that of China's. 
5. Indeed, China perhaps should be given credit for having done as well as it has, given its low expenditures on health - estimated to be between 2\% to 3\% of GDP (see http://earthtrends. wri.org/text/environmental-governance/variable-642.html). (By contrast, the US spends approximately $15 \%$ of its GDP on health.

6. So evident in the United States, where in recent years, GDP has been increasing, while median household income has been falling - even looking just at income, most Americans today are worse off than they were five years ago; but if account is taken of the increased health insecurity with more than 46.6 millions without health insurance, a number that continues to rise every year - the deterioration in standards of living is even more marked. See US Census Bureau (2006).

7. In particular, my discussion focused on the so-called 'market failures', instances such as environmental externalities where markets by themselves may not lead to efficient outcomes.

8. Premier Wen Jiabao called attention to the critical shortfall in energy and pollutants: While energy consumption per unit of GDP dropped by $1.2 \%$ in 2006 - an impressive achievement, especially compared to the increases of $4.9 \%, 5.5 \%$, and $0.2 \%$ in the previous three years the target was to reduce energy consumption per unit GDP by 4\%. (Wen, 2007). Still, China's achievements in increasing energy efficiency and reducing emissions should be noted: between 1990 and 2002, China increased its $\mathrm{CO}_{2}$ emissions per unit GDP by more than 50\%, while the world average decreased by less than $20 \%$. See Wang Mengkui et al. (2007).

9. Even as China has changed its economic model, it has continued to focus on broader objectives than just increasing in GDP, i.e. equitable and sustainable increases in living standards. Measures like green GDP and the UNDP's HDI may provide a better measure of success than GDP per capita.

10. The US would simply shift purchasing textiles, for instance, from China to Bangladesh or Cambodia; these countries are more likely to spend the increased income thereby generated in their own countries; and if they did decide to hold more foreign reserves, it is more likely that they would hold a larger fraction of their reserves in the euro than in the dollar, which is increasingly seen as a weak and weakening currency. For further elaboration on this, see Stiglitz (2006b).

11. For an extended discussion of the advantages of export taxes over exchange rate revaluation, see Lau and Stiglitz (2005).

12. This is particularly true because the financial sector in China is dominated by the four big state banks. Only about $1 \%$ of the firms in China, mainly the large firms, have borrowed money from banks. Due to the underdevelopment of small- and medium-sized banks which typically provide credit to local, small- and medium-sized firms, small- and middle-sized enterprises and family farms often do not receive financial services from banks and need to finance their investment through their own savings, one of the factors contributing to China's high savings rate.

13. The lending is done at the country level, though the purchases of the goods have occurred at the level of individual firms and households.

14. It is even more peculiar to think of China having helped finance America's huge fiscal deficit, arising partly from the Iraq War, partly from the tax cut - for the richest people in the richest country in the world.

15. I would argue, accordingly, that Korean Chaebols should not be a model of China's business organization.

16. Although it will still be important for China to guard itself against abusive lending practices, and to adopt bankruptcy laws which do not reward financial institutions for making bad loans. There is concern that recent changes in bankruptcy law in the United States have done just that, and are contributing to stresses among lower- and even middle-income individuals, who already face problems of stagnant incomes. These problems have been compounded by the fact that more than 50 million Americans do not have health insurance; some studies suggest that a significant fraction of individuals who are forced into personal bankruptcy have confronted major medical expenses. There are important lessons from these experiences for China. China is also expanding uncollateralized consumer debt, e.g. credit cards. The experience of Korea provides a cautionary note, which Chinese regulators say they have taken into account.

17. One must be wary of these numbers. Some analysts argue that it represents a gross overestimate of the 'true' trade surplus because a portion, possibly a substantial portion, of the sharp increase in trade surplus is due to over-invoicing export and under-invoicing import by the trading companies for the purpose of gaining from the anticipated RMB revaluation. Two ways to discourage this practice are: (a) for the Chinese government to make it clear that the appreciation 
will not exceed, say 3-4\% per year; and (b) for capital gains taxes to be imposed, at high rates, especially on short term capital gains associated with currency appreciation. By contrast, some argue that the large bilateral trade surplus with the US understates that surplus because some of the imports to the US from places like Hong Kong are really of goods made largely in China.

18. For instance, according to the Economist Intelligent Unit (xxxx?), GDP in 2006 is estimated to have grown at $11.1 \%$, but rural and urban household consumption at only $8.6 \%$ and $7.6 \%$ respectively (National Bureau of Statistics of China, 2007).

19. Technically, what is required is that the marginal propensity to consume out of income of the rich is lower than that of the poor.

20. According to the 2004 Economic Census (National Bureau of Statistics of China, 2006), the number of small industrial and commercial enterprises was 39.2 million; by 2006, the number was reduced to 25.7 million.

21. Some have argued that China should rely on a privately financed healthcare system. No country has succeeded in establishing a fundamentally private healthcare system that both is efficient and provides adequate care for the poor. America has among the most privatized healthcare systems among the advanced industrial countries; healthcare expenditures as a percentage of GDP is the highest in the world, and healthcare outcomes are far poorer than those in other advanced industrial countries of comparable income. Standard theories of asymmetric information (particularly focusing on adverse selection) explain why private provision of healthcare insurance is inefficient, marked in particular by high transaction costs. Some of the recent 'reforms' encouraging private insurance have exacerbated problems of 'cream skimming', and are probably contributing to the increasing problems of lack of coverage.

22. As always, there is some debate about the numbers. Some argue that GDP and savings are both overstated, because included in real estate investment is the value of land (there are often large capital gains associated with real estate developments; value of the capital gain on the land should be treated as a transfer payment, but typically is not). Others argue that there is underreporting of services; an earlier correction lead to a marked decrease in the savings ratio; some argue that there is still some underreporting. Finally, some believe that there is overreporting of exports and underreporting of imports, as part of circumvention of short-term capital controls. In this view, a substantial part of the current account surplus is speculative capital flows. Taking this into account would again lower the domestic savings rate.

23. Even within the advanced industrial countries, there are huge disparities between best and average practices, implying there is typically considerable scope for increases in overall efficiency.

24. I argued similarly in my book Making globalization work, Chapter 8 (Stiglitz 2006b).

25 . With each country keeping the revenue from the carbon tax, the distributional consequences arise from the differences in the deadweight losses associated with the imposition of the carbon tax relative to the imposition of alternative taxes. In many cases, the switch towards a carbon tax would actually be welfare enhancing. Even for countries that have already optimized their tax structure, the social cost is measured by the difference in the Harberger triangles, and the differences in the social cost are related to the differences in these differences, which are likely to be small.

26. There are several reasons why a poorly designed patent system may impede the pace of innovation. Knowledge is the most important input into the production of knowledge; by making knowledge less accessible, the pace of innovation will be reduced. This can be partially mitigated by disclosure requirements; interestingly, some advocates of strong intellectual property rights have argued that disclosure violates their property rights. As we shall explain later, all rights are associated with responsibilities, and one of the responsibilities long associated with good intellectual property regimes is a responsibility of full disclosure.

Another reason is that intellectual property can lead to increased monopolization, and it has long been recognized that monopolies have less of an incentive to innovate than do competitive markets. The ability of a monopolist like Microsoft to squash successful innovators like Netscape, who innovated in the area of browsers, and RealNetwork, which innovated in the area of media players, almost surely has an enervating effect on innovation - another reason why countries need strong anti-trust laws.

Still a third problem arises from 'patent thickets', the uncertainties that innovators face that their innovation will trespass on the intellectual property on others.

27. The fact that there is no single best IP system is exhibited by the conflicts of views over the use of labelling, where many European countries arguing for tight protection of the use of labelling (e.g. of names like Parma ham) and the US, which more often copies these labels from other 
countries, arguing on the other side. For China, the development of strong trademark protection is important in providing incentives for the development of brand name reputations associated with the production of high quality goods.

28. The prize system works best when there are well-defined objectives - a cure for a disease, a light long-lived battery for running a car, a more fuel efficient engine. The Royal Society of Arts in the UK has long advocated and used prizes for stimulating innovation.

29. For a fuller discussion of the prize system, and the problems with the patent system, see my recent book Making globalization work, Chapter 5 (Stiglitz 2006b).

30. There are a host of examples of this. Developing countries have been particularly concerned with 'biopiracy', the patenting of traditional knowledge. Among the oft-cited examples are the patents granted by the US for basmati rice, the healing properties of turmeric, and neem oil.

31. For instance, the dynamic benefits of extending the lifetime of copyright (especially for copyrights already granted) to 70 years beyond the lifetime of the author almost surely were less than the static costs.

32. One of the reasons is that the US and the drug companies often put enormous pressure on countries not to issue these compulsory licenses.

33. There is broad consensus within these countries about the desirability of their model, though, as usual, there are differences in views concerning 'fine tuning' of the system. Thus, the recently elected government in Sweden has called for some reduction in social benefits - but even with those reductions, the level of social protection will be far stronger than, say, in the United States.

34. These 'transaction costs', of course, provide much of the motivation: they represent an important source of income to financial markets.

35. This view is often associated with Ronald Coase (1960), and has been popularized by Hernando De Soto (2000). It was suggested, for instance, that even problems of externalities could be handled efficiently; 'all' one had to do was to determine who had the property rights over air. In fact, however, Coase's 'conjecture' about the role of property rights has been shown to have limited applicability: there has to be essentially perfect information and zero transaction costs. With transactions costs and imperfect information, Coasian bargaining will in general lead to inefficient resource allocations. But even were Coase's conjecture correct, in some sense, it would leave open the difficult question of the assignment of property rights, which could have large distributional consequences.

36. Earlier, in the 1950s, AT\&T agreed in response to anti-trust action against it to make its patents available to others.

37. As a result of exacerbating the significance of agency costs, e.g. associated with tenancy relationships. See, e.g. Braverman and Stiglitz (1989, 185-201). Mild restrictions on property rights - for instance, allowing workers to borrow against the produce of the land, but not against the land itself - can reduce the likelihood of these undesirable outcomes.

38. There are important administrative issues concerning the point of collection, which I do not have time to address here.

39. For a discussion of implications of imperfect information for monetary policy, see Stiglitz (2004a, 2006a).

40. And individuals with finite lives. See, e.g. Stiglitz (2004b). For a discussion of why financial market liberalization may not be desirable, see, e.g. Stiglitz and Greenwald (2003).

41. For instance, subsidizing loss-making, state-owned enterprises.

42. Justin Lin has argued that this is far from the most important reason, simply because the real reason that national savings is so high has to do with high corporate savings, not high household savings. In fact, Chinese households' saving is not particularly high compared to other developing countries. For example, China's household saving in 2005 was 16\% of GDP, and even at its peak, in 1996, it was only $20 \%$ of GDP, whereas India's was $22 \%$. What makes China's saving rate so high is the corporate saving, which is more than $20 \%$ of GDP.

43. Better private insurance would also reduce the need for precautionary savings; but especially in the area of health, there cannot be reliance on private insurance. Private insurance will devote excessive efforts to 'cream skimming', resulting in high transactions costs and large distortions.

44. For instance, the urbanization level increased from $36.2 \%$ to $43 \%$ in the five years from 2000 to 2005. The increased percentage of urbanization was larger than that in the 25 years from 1953 to 1978. See Wang et al. (2007).

45. See, for instance, my Nobel lecture, 'Information and the hange in the paradigm in economics' (Stiglitz 2002). My book Roaring Nineties (Stiglitz 2003a) provided a popular account of how 
these information imperfections had led to the bubble of the 1990s, and its subsequent crashing, at such cost to the American economy.

\section{References}

Braverman, A. and J.E. Stiglitz. 1989. Credit rationing, tenancy, productivity and the dynamics of inequality. In The economic theory of agrarian institutions, ed. P. Bardhan, 185-201. Oxford: Clarendon Press.

Coase, Ronald H. 1960. The Problem of Social Cost. Journal of Law and Economics, 3(1), 1-44.

De Soto, Hernando. 2000. The Mystery of Capital: Why Capitalism Triumphs in the West and Fails Everywhere Else. New York: Basic Books

Greenwald, Bruce and J.E. Stiglitz. 2006. Helping infant economies grow: Foundations of trade policies for developing countries. American Economic Review: AEA Papers and Proceedings 96, no. 2 (May): 141-6.

Feldstein, Martin. 2007. New directions for China's growth: The role of taxes and fiscal policies. Paper presented to the China Development Forum, 18 March, in Beijing, China.

Lau, L. and J.E. Stiglitz. 2005. China's alternative to revaluation, Financial Times, 25 April.

National Bureau of Statistics of China. 2006. 2004 China Economic Census Yearbook. Beijing: China Statistics Press. (Zhongguo Jingji Pucha Nianjian 2004)

National Bureau of statistics of China. 2007. China Statistical Yearbook. Beijing: China Statistics Press. (Zhongguo Tongji Nianjian 2007)

Orszag, Peter and J.E. Stiglitz. 2001. Rethinking pension reform: Ten myths about social security systems. In New ideas about old age security, ed. R. Holman and J.E. Stiglitz, 17-56. Washington: World Bank.

Prasad, E., K. Rogoff, S. Wei, and A.M. Kose. 2003. Effects of financial globalization on developing countries: Some empirical evidence. IMF Occasional Paper, No. 220, (September).

Sen, Amartya. 2006. Human development and health. Lecture delivered at the International Conference on Health and Development, October, in Peking University, China.

Stern, Nicholas. 2006. Stern Review Report on the Economics of Climate Change. London: Cambridge University Press.

Stiglitz, J.E. 2002. Information and the change in the paradigm in economics. In Les Prix Nobel; The Nobel Prizes 2001, ed. Tore Frangsmyr, 472-540, Stockholm: The Nobel Foundation. (Also published in Revista Asturiana De Economia 25 (December): 95-164; an abbreviated version is available in American Economic Review 92, no. 3 (June): 460-501.)

Stiglitz, J.E. 2003a. Roaring nineties. New York: W.W. Norton \& Company.

Stiglitz J.E. 2003b. On liberty, the right to know, and public discourse: the role of transparency in public life. In Globalizing rights: The Oxford Amnesty Lectures 1999, ed. Mathew J. Gibney, 115-56. London: Oxford University Press.

Stiglitz, J.E. 2004a. Banking disntermediation and its implication to monetary policy (keynote address). In Banking disintermediation and its implication to monetary policy: Theoretical views and countries' experiences, ed. Charles Joseph, 1-11. Proceedings of an international seminar sponsored by the Bank Indonesia and Asian Development Bank, December, in Denpasar, Bali, Indonesia.

Stiglitz, J.E. 2004b. Capital-market liberalization, globalization and the IMF. Oxford Review of Economic Policy 20, no. 1 (Spring): 57-71.

Stiglitz, J.E. 2006a. Development and finance: Insights from the new paradigm of monetary economics. The Tenth Sir Arthur Lewis Memorial Lecture, 1 November 2005, in Basseterre, St Kitts and Nevis. In Economic theory and development options: The legacy of W. Arthur Lewis, ed. Eastern Caribbean Central Bank, Kingston: Ian Randle Publishers, 191-209.

Stiglitz, J.E. 2006b. Making globalization work. New York: W.W. Norton \& Company.

Stiglitz, J.E. and Bruce Greenwald. 2003. Towards a new paradigm in monetary economics. London: Cambridge University Press.

Stiglitz, J.E. and Bruce Greenwald. 2003. Towards a new paradigm for monetary policy. London: Cambridge University Press. 
Wang Mengkui, Li Jiange, Lu Zhongyuan, Hou Yongzhi, Shi Yaodong, Liu Peilin, and Qin Zhongchun. 2007. China: Accelerating structural adjustment and growth pattern change. Paper presented at the China Development Forum, 18 March, in Beijing, China.

US Census Bureau. 2006. Income, poverty, and health insurance coverage in the United States: 2005, US Census Bureau Health Insurance Data, August.

Wen, Jiabao. 2007. Report on the work of the government. Report delivered at the Fifth Session of the Tenth National People's Congress, 5 March, in Beijing, China. 
Copyright of China Economic Journal is the property of Routledge and its content may not be copied or emailed to multiple sites or posted to a listserv without the copyright holder's express written permission. However, users may print, download, or email articles for individual use. 